ARTIKEL PENELITIAN

\title{
Korelasi antara indeks massa tubuh dan profil lipid pada remaja obesitas di Kota Palembang
}

\author{
Subandrate ${ }^{1}$, Sadakata Sinulingga ${ }^{1}$, Eka Febri Zulissetiana ${ }^{2}$, Susilawati $^{3}$, Dwi Indira Setyorini $^{4}$, \\ Ella Amalia ${ }^{5}$ \\ 1. Bagian Biokimia dan Kimia Medik, Fakultas Kedokteran Universitas Sriwijaya; 2. Bagian Fisiologi, \\ Fakultas Kedokteran Universitas Sriwijaya; 3. Bagian Patologi Klinik, Fakultas Kedokteran Universitas \\ Sriwijaya; 4. Bagian Penyakit Dalam, RSI. Siti Khodijah Palembang; 5. Bagian Mikrobiologi, Fakultas \\ Kedokteran Universitas Sriwijaya
}

Korespondensi: Subandrate; alamat e-mail: subandrate@unsri.ac.id

\begin{abstract}
Abstrak
Latar Belakang: Obesitas merupakan suatu akumulasi lemak yang abnormal dan berlebihan. Selain pada orang dewasa, obesitas juga terjadi pada remaja, dengan jumlah penderitanya yang semakin meningkat. Obesitas memiliki resiko terjadinya penyakit, seperti hipertensi, aterosklerosis, dan sindrom metabolik. Oleh karena itu, diperlukan adanya penelitian mengenai hubungan indeks massa tubuh (IMT) dan profil lipid remaja obesitas di Kota Palembang. Tujuan: Penelitian ini bertujuan untuk mengetahui korelasi antara IMT dan profil lipid pada remaja obesitas di Kota Palembang. Metode: Penelitian ini adalah penelitian analitik observasional dengan desain potong lintang terhadap 143 remaja di Kota Palembang. IMT dihitung berdasarkan berat badan $(\mathrm{kg})$ dan tinggi badan $(\mathrm{m})$. Kadar profil lipid berupa kolesterol total, trigliserida, LDL-kolesterol, dan HDL-kolesterol darah diperiksa menggunakan kit dari Human ${ }^{\circledR}$ di Laboratorium Kimia Dasar Fakultas Kedokteran Universitas Sriwijaya. Analisis data menggunakan uji korelasi Pearson. Hasil: Dari penelitian ini didapatkan sekitar 29,4\% remaja di Kota Palembang mengalami obesitas dan sekitar $17,5 \%$ remaja mengalami dislipidemia. Uji korelasi Pearson menghasilkan nilai korelasi antara IMT dan kolesterol total $(r=0,141 ; p=0,093)$, trigliserida $(r=0,260 ; p=0,002)$, LDL-kolesterol $(r=0,002 ; p=0,983)$, dan HDL-kolesterol $(r=0,096$; $\mathrm{p}=0,256)$. Korelasi IMT dengan kadar kolesterol total, LDL-kolseterol, dan HDL-kolesterol tidak bermakna $(p>0,05)$. Akan tetapi, korelasi IMT dengan kadar trigliserida bermakna $(p<0,05)$ dengan arah korelasi postif dan kekuatan lemah $(r=0,2-0,4)$. Simpulan: Pada remaja, tidak ada korelasi IMT dengan kadar kolesterol total, LDL-kolseterol, dan HDL-kolesterol. Terdapat korelasi positif antara IMT dan kadar trigliserida pada remaja.
\end{abstract}

Kata kunci: Indeks massa tubuh; profil lipid; obesitas; remaja

\section{Abstract}

Background: Obesity is an abnormal and excessive accumulation of fat. Apart from adults, obesity also occurs in adolescents, with an increasing number of sufferers. Obesity is known to have a risk to develop several diseases, such as hypertension, atherosclerosis, and metabolic syndrome. Therefore, it is necessary to research the relationship between body mass index (BMI) and lipid profile of obese adolescents in Palembang City. Objective: This study aims to determine the correlation between BMI and lipid profile in obese adolescents in Palembang City. Method: This study was an observational 
analytic study with a cross-sectional design of 143 adolescents in Palembang City. BMI is calculated based on body weight $(\mathrm{kg})$ and height $(\mathrm{m})$. Lipid profile levels in the form of total cholesterol, triglycerides, LDL-cholesterol and HDL-cholesterol in blood were examined using a kit from Human ${ }^{\circledR}$ at the Basic Chemistry Laboratory, Faculty of Medicine, Universitas Sriwijaya. Data analysis using Pearson correlation test. Results: From this study it was found that around $29.4 \%$ of adolescents in Palembang were obese and around 17.5\% of adolescents had dyslipidemia. The Pearson correlation test yields correlation value between BMI and total cholesterol $(r=0,141 ; \quad p=0,093)$, triglycerides $(r=0,260 ; p=0,002), L D L$-cholesterol $(r=0,002 ; p=0,983)$, and HDL-cholesterol $(r=0,096$; $p=0,256)$. The correlation of BMI with total cholesterol, $L D L$-cholesterol and HDL-cholesterol were not significant $(p>0,05)$. However, the correlation of $B M I$ with triglyceride levels was significant $(p<0,05)$ with positive correlation direction and weak strength $(r=0,2-0,4)$. Conclusion: In adolescent, there is no correlation of BMI with total cholesterol, LDL-cholesterol and HDL-cholesterol. There is a positive correlation between $\mathrm{BMI}$ and triglyceride levels in adolescents

Keywords: Adolescents; body mass index; lipid profile; obesity

\section{PENDAHULUAN}

Obesitas merupakan suatu akumulasi lemak yang abnormal dan berlebihan yang menyebabkan risiko terhadap kesehatan. ${ }^{1,2}$ Jumlah penduduk obesitas terus mengalami peningkatan dari tahun ke tahun. Prevalensi penduduk dewasa obesitas pada tahun 2018 sebanyak 21,8\%, lebih tinggi dari tahun 2007 (10,5\%) dan tahun 2010 (14,8\%). ${ }^{2}$ Prevalensi penduduk dengan berat badan lebih juga mengalami peningkatan, dari $8,6 \%$ pada tahun 2007 dan $11,5 \%$ pada tahun 2013 menjadi 13,6\% pada tahun $2018 .^{2}$

Saat ini obesitas tidak hanya menjadi masalah orang dewasa, tetapi juga menjadi masalah kesehatan pada anak dan remaja. Berat badan lebih dan obesitas pada remaja terutama terjadi pada negara berkembang. Data WHO menunjukkan bahwa sekitar 4-14\% remaja mengalami obesitas. ${ }^{1,2}$ Penelitian di Kota Padang menujukkan sekitar 5\% remaja SMA mengalami obesitas. ${ }^{3}$ Obesitas merupakan faktor risiko berbagai penyakit seperti kardiovaskuler, sleep apneu, osteoartritis, dan diabetes melitus. ${ }^{1,2}$

Obesitas telah lama dikaitkan dengan dislipidemia. Pada obesitas, kadar trigliserida, kadar kolesterol, dan kadar LDL cenderung meningkat dan kadar HDL cenderung menurun. Dislipidemia pada obesitas tentunya akan meningkatkan risiko penyakit-penyakit kardiovaskuler yang dapat terjadi terutama pada individu dengan obesitas. ${ }^{4}$ Pada anak-anak dan remaja, banyak studi mengindikasikan bahwa dislipidemia dan obesitas memiliki hubungan yang positif dan hal ini dihubungkan dengan komplikasi kardiometabolik, seperti hipertensi, aterosklerosis, dan sindrom metabolik. Data riset kesehatan dasar pada tahun 2018 menunjukkan bahwa sekitar 39\% penduduk berusia $>15$ tahun mengalami 
dislipidemia. $^{2}$ Penelitian lain yang dilakukan di Sulawesi menyebutkan bahwa sekitar $11 \%$ remaja mengalami dislipidemia. $^{5}$

Peningkatan prevalensi obesitas dan dislipidemia tidak lepas dari perubahan pola hidup pada remaja sekarang. Pola hidup sedentari dan kemudahan akses terhadap teknologi informasi menjadi faktor risiko peningkatan angka obesitas dan dislipidemia. Saat ini remaja lebih menyukai makan-makanan tinggi kalori seperi fast food, junk food, dan sea food, sementara aktifitas fisik yang mereka lakukan cenderung lebih sedikit.., ${ }^{1,2}$

Mengingat semakin meningkatnya angka obesitas dan dislipidemia pada remaja, juga untuk melakukan tindakan preventif terjadinya komplikasi kardiometabolik, maka perlu dilakukan penelitian mengenai hubungan IMT dan profil lipid remaja obesitas di Kota Palembang.

\section{METODE}

Penelitian ini adalah penelitian analitik observasional dengan pendekatan potong lintang. Sebanyak 143 remaja di Kota Palembang dijadikan subyek penelitian secara acak. Derajat obesitas subyek penelitian ditentukan menurut IMT berdasarkan berat badan $(\mathrm{kg})$ dan tinggi badan $(\mathrm{m})$. Berat badan ditimbang menggunakan timbangan berat badan manual (OneMed) dan tinggi badan diukur menggunakan stature metre 2 meter (oneMed). Nilai IMT dikategorikan sesuai
Kementerian Kesehatan Republik Indonesia. ${ }^{2}$

Profil lipid yang diukur dalam penelitian ini meliputi kolesterol total, trigliserida, LDLkolesterol, dan HDL-kolesterol. Sampel darah diambil dari vena mediana kubiti sebanyak kurang lebih $3 \mathrm{~mL}$ menggunakan spuit untuk dilakukan pemeriksaan profil lipid. Pemeriksaan profil lipid menggunakan cholesterol kit, triglyceride kit, LDL-cholesterol kit, dan HDLcholesterol kit dari Human ${ }^{\circledR}$. Pemeriksaan kadar profil lipid dilakukan di Laboratorium Kimia Dasar Fakultas Kedokteran Universitas Sriwijaya. Analisis data dilakukan dengan menggunakan uji korelasi Pearson menggunakan SPSS 24.

\section{HASIL DAN PEMBAHASAN}

Dalam penelitian ini, didapatkan 143 subyek penelitian yang merupakan remaja di Kota Palembang yang terdiri dari $27 \%$ laki-laki dan $73 \%$ perempuan. Sebagian besar subyek penelitian berumur 18 (1621) tahun dengan rerata IMT masuk kategori gemuk $(25,1 \pm 5,3)$. Karakteristik subyek penelitian dapat dilihat pada tabel 1. 
Tabel 1. Karakteristik subjek

\begin{tabular}{|c|c|c|c|}
\hline \multicolumn{2}{|c|}{ Karakteristik } & $\mathbf{n}$ & $\%$ \\
\hline \multirow{3}{*}{$\begin{array}{l}\text { Jenis } \\
\text { Kelamin }\end{array}$} & Laki-laki & 39 & 27 \\
\hline & Perempuan & 104 & 73 \\
\hline & Jumlah & 143 & 100 \\
\hline $\begin{array}{l}\text { Usia } \\
\text { (tahun) }\end{array}$ & Rerata & \multicolumn{2}{|c|}{$18,2 \pm 0,9$} \\
\hline \multirow{6}{*}{$\begin{array}{l}\text { IMT } \\
\left(\mathrm{kg} / \mathrm{m}^{2}\right)\end{array}$} & Rerata & \multicolumn{2}{|c|}{$25,1 \pm 5,3$} \\
\hline & $\begin{array}{l}\text { Kurus } \\
(<18,5)\end{array}$ & 12 & 8,4 \\
\hline & $\begin{array}{l}\text { Normal } \\
(18,5- \\
24,9)\end{array}$ & 63 & 44,1 \\
\hline & $\begin{array}{l}\text { Gemuk } \\
(25-27)\end{array}$ & 26 & 18,2 \\
\hline & $\begin{array}{l}\text { Obesitas } \\
(>27)\end{array}$ & 42 & 29,4 \\
\hline & Jumlah & 143 & 100 \\
\hline
\end{tabular}

Dari tabel 1, dapat diketahui bahwa sekitar $29,4 \%$ remaja dalam penelitian ini mengalami obesitas dan $18,2 \%$ mulai mengalami kegemukan. Hasil penelitian ini lebih tinggi dibandingkan dengan penelitian sebelumnya yakni prevalensi obesitas pada remaja sekitar $14 \% .^{5,6} \mathrm{Hal}$ ini dapat disebabkan adanya perbedaan pada populasi penelitian, dimana pada penelitian ini populasi cenderung homogen dan sebagian besar subyek penelitian merupakan kelompok ekonomi menengah ke atas. Faktor intake nutrisi berperan penting dalam menentukan berat badan seseorang, seperti pada kelompok masyarakat ekonomi menengah ke atas yang cenderung memiliki kemampuan mendapatkan makanan secara berlebih. Selain itu, saat ini ada perubahan pola hidup remaja yang lebih menyukai gaya gidup sedentari, yaitu diet tinggi kalori dan rendah aktivitas fisik. Ciri hidup seperti ini juga dipermudah dengan adanya kemajuan informasi teknologi. Akibatnya, para remaja rentan mengalami berat badan berlebih. ${ }^{1,2,7,8}$ Pemberian edukasi dan intervensi yang cepat dan tepat diharapkan dapat mengurangi jumlah remaja obesitas. ${ }^{8,9}$

Profil lipid darah yang diperiksa dalam penelitian ini meliputi kadar kolesterol total, kadar trigliserida, kadar LDLkolesterol, dan Kadar HDL-kolesterol. Tabel 2 menunjukkan kadar profil lipid subyek penelitian.

Table 2. Kadar profil lipid subyek penelitian

\begin{tabular}{lccc}
\hline \multicolumn{1}{c}{ Profil Lipid } & $\begin{array}{c}\text { Jumlah } \\
(\mathbf{N}=\mathbf{1 4 3})\end{array}$ & $\begin{array}{c}\text { Rerata } \pm \text { SD } \\
(\mathbf{m g} / \mathbf{d l})\end{array}$ \\
\hline \multirow{2}{*}{ Kolesterol } & Normal & 143 & $151,7 \pm 16,5$ \\
& Tinggi & 0 & \\
Trigliserida & Normal & 143 & $125,8 \pm 33,5$ \\
& Tinggi & 0 & \\
LDL- & Normal & 143 & \\
Kolesterol & Tinggi & 0 & $82,3 \pm 15,8$ \\
HDL- & Normal & 118 & \\
Kolesterol & Rendah & 25 & $47,8 \pm 12,3$ \\
\hline
\end{tabular}

Hasil penelitian menunjukkan bahwa profil lipid remaja dalam penelitian ini rata-rata normal baik laki-laki maupun perempuan. Kadar kolesterol kurang dari $200 \mathrm{mg} / \mathrm{dL}$, kadar trigliserida kurang dari $200 \mathrm{mg} / \mathrm{dL}$, kadar LDL-kolesterol kurang dari 130 $\mathrm{mg} / \mathrm{dL}$, dan kadar HDL-kolesterol lebih dari $40 \mathrm{mg} / \mathrm{dL}$ dikategorikan sebagai profil lipid normal. Akan tetapi, ada sekitar 17,5\% remaja yang memiliki kadar HDL-kolesterol rendah, yaitu 5 orang laki-laki dan 20 orang perempuan. Dengan demikian, dapat dikatakan bahwa dalam penelitian ini hanya sekitar $17,5 \%$ remaja mengalami 
dislipidemia. Hasil ini lebih tinggi daripada hasil penelitian yang sebelumnya yakni $11 \%{ }^{5}$ Perbedaan pada populasi penelitian dapat menjadi penyebab berbedanya hasil penelitian. Penelitian ini dilakukan pada remaja dengan tingkat ekonomi menengah ke atas. Penurunan kadar HDL-kolesterol pada remaja dapat disebabkan diet tinggi asam lemak tak jenuh dan aktivitas fisik yang rendah. ${ }^{1,4,9}$

Lipid adalah makromolekul yang dibutuhkan oleh tubuh dalam jumlah yang optimum. Kelebihan lemak dapat disimpan sebagai cadangan makanan. Selama ini ada anggapan bahwa obesitas menyebabkan kadar profil lipid menjadi tinggi (dislipidemia) dan sebaliknya kadar profil lipid yang tinggi dapat menyebabkan obesitas. $^{10,11}$

Tabel 3. Kadar profil lipid menurut IMT

\begin{tabular}{lcccc}
\hline \multicolumn{1}{|c}{$\begin{array}{c}\text { IMT } \\
\left(\mathbf{k g} / \mathbf{m}^{2}\right)\end{array}$} & $\begin{array}{c}\text { Kolesterol } \\
\text { Total } \\
(\mathbf{m g} / \mathbf{d L})\end{array}$ & $\begin{array}{c}\text { Trigliserida } \\
(\mathbf{m g} / \mathbf{d L})\end{array}$ & $\begin{array}{c}\text { LDL- } \\
\text { Kolesterol } \\
(\mathbf{m g} / \mathbf{d L})\end{array}$ & $\begin{array}{c}\text { HDL- } \\
\text { Kolesterol } \\
(\mathbf{m g} / \mathbf{d L})\end{array}$ \\
\hline $\begin{array}{l}\text { Kurus } \\
(<18,5)\end{array}$ & $148,3 \pm 17,5$ & $114,2 \pm 36,7$ & $85,5 \pm 17,8$ & $48,1 \pm 13,9$ \\
$\begin{array}{l}\text { Normal } \\
(18,5-\end{array}$ & $149,7 \pm 16,3$ & $118,5 \pm 33,6$ & $81,6 \pm 14,7$ & $48,7 \pm 13,9$ \\
$24,9)$ & & & & \\
$\begin{array}{l}\text { Gemuk } \\
(25-27)\end{array}$ & $153,6 \pm 17,9$ & $133,7 \pm 31,0$ & $82,3 \pm 17,7$ & $48,5 \pm 10,1$ \\
$\begin{array}{l}\text { Obesitas } \\
(>27)\end{array}$ & $154,5 \pm 15,7$ & $135,2 \pm 31,4$ & $82,6 \pm 16,0$ & $45,9 \pm 10,6$ \\
\hline
\end{tabular}

Dari tabel 3 dapat dilihat bahwa orang kurus cenderung memiliki kadar kolesterol dan trigliserida yang lebih rendah dibandingkan orang gemuk. Kadar HDLkolesterol pada orang obesitas lebih tinggi dibandingkan dengan orang normal, sementara kadar LDL-kolesterol pada semua kelompok IMT tidak jauh berbeda. Penelitian yang dilakukan oleh Tandra et al. dan Reuter et al. menunjukkan bahwa dislipidemia cenderung terjadi pada orang obesitas dibandingkan tidak obesitas. ${ }^{12,13}$ Untuk melihat hubungan tersebut dilakukan uji korelasi IMT dengan kadar profil lipid. Hasil uji korelasi antara IMT dan kadar profil lipid dapat dilihat pada tabel 4.

Tabel 4. Uji korelasi IMT dan kadar profil lipid

\begin{tabular}{lcccc}
\hline ol & $\begin{array}{c}\text { Kolester } \\
\text { ol }\end{array}$ & $\begin{array}{c}\text { Trgiliseri } \\
\text { da }\end{array}$ & $\begin{array}{c}\text { LDL- } \\
\text { Kolester } \\
\text { ol }\end{array}$ & $\begin{array}{c}\text { HDL- } \\
\text { Kolester } \\
\text { ol }\end{array}$ \\
\hline IM & $r=0,141$ & $r=0,260$ & $r=0,002$ & $r=0,096$ \\
T & $p=0,093$ & $p=0,002$ & $p=0,983$ & $p=0,256$ \\
& $n=143$ & $n=143$ & $n=143$ & $n=143$ \\
\hline
\end{tabular}

Uji Korelasi Pearson, bermakna bila $p<0,05$.

Dari tabel 4 dapat dilihat bahwa tidak ada korelasi antara IMT dengan kadar kolesterol total, LDL-kolesterol, dan LDLkolesterol $(p>0,05)$. Walaupun demikian, dapat dilihat bahwa peningkatan IMT akan menaikkan kadar kolesterol total, LDLkolesterol, dan HDL-kolesterol walaupun rendah $(r=0,2-0,4)$. Hasil penelitian ini sedikit berbeda dengan penelitian yang dilakukan di Bitung bahwa ada perbedaan kadar kolesterol dan LDL-kolesterol antara remaja obesitas dan tidak obesitas. ${ }^{12}$

Hal ini dapat terjadi karena kolesterol total, LDL-kolesterol, dan LDL-kolesterol bukan merupakan komponen lipid yang menyusun simpanan lemak tubuh. Ketiga komponen lemak tersebut terutama lebih berfungsi dalam pengangkutan atau sebagai prekursor dalam metabolism tubuh. ${ }^{10,11}$

Akan tetapi, tabel 4 juga memperlihatkan bahwa terdapat korelasi antara IMT dan 
kadar trigliserida walaupun dengan kekuatan yang rendah. Ini berarti bahwa setiap peningkatan IMT akan menaikan kadar trigliserida dan sebaliknya. Penelitian yang dilakukan oleh Elmaogullari et al. menyebutkan bahwa hipertrigliserida pada obesitas remaja sekitar $21,9 \%$. Trigliserida merupakan lipid yang terdiri dari 3 asam lemak dan gliserol. Kadar trigliserida dalam darah terutama berasal dari diet tinggi lipid dan karbohidrat. Dalam keadaan kenyang, hormon insulin meregulasi metabolisme trigliserida sehingga trigliserida disimpan sebagai cadangan makanan dalam sel adiposit. Dengan demikian, trigliserida dalam darah yang tinggi akan diangkut dan disimpan di jaringan adiposit sehingga akan menambah berat badan (IMT). ${ }^{10,11,14}$

Dalam penelitian ini, dapat dikatakan bahwa pada remaja profil lipid dan obesitas tidak berhubungan. Selain beberapa hal yang disebutkan di atas, faktor yang diduga turut berperan adalah masih tingginya tingkat metabolik dalam usia muda. Metabolisme yang cepat menyebabkan bentuk suatu senyawa tidak menetap dalam bentuk tertentu tetapi cepat berubah ke bentuk lain yang lebih dibutuhkan. Akan tetapi, obesitas dan dislipidimia pada remaja patut tetap diwaspadai mengingat beberapa penyakit metabolik lain masih terkait dengan kelainan ini. ${ }^{10,11,15}$

\section{KESIMPULAN}

Profil lipid pada remaja cenderung normal baik obesitas ataupun tidak obesitas. IMT pada remaja tidak berkorelasi dengan kadar kolesterol total, kadar LDLkolesterol, dan kadar HDL-kolesterol. IMT pada remaja berkorelasi positif lemah dengan kadar trigliserida. Perlu dilakukan penelitian lebih lanjut yang memperhatikan aspek diet, aktivitas fisik, dan keadaan berpuasa pada remaja obesitas.

\section{DUKUNGAN FINANSIAL}

Penelitian ini didanai oleh Hibah Sains, Teknologi, dan Seni Fakultas Kedokteran Universitas Sriwijaya tahun 2019.

\section{UCAPAN TERIMA KASIH}

Terima kasih kepada Wakil Dekan III Fakultas Kedokteran Universitas Sriwijaya yang membantu dan memfasilitasi pengumpulan subyek penelitian dan pengambilan sampel penelitian.

\section{KONFLIK KEPENTINGAN}

Penulis tidak memiliki konflik kepentingan dalan penelitian ini. 


\section{DAFTAR PUSTAKA}

1. WHO Regional Office for Europe. Adolescent obesity and related behaviours: trends and inequalities in the WHO European Region, 2002-2014. Copenhagen: World Health Organization; 2017. $98 \mathrm{p}$.

2. Badan Penelitian dan Pengembangan Kesehatan. Laporan Nasional Riskesdas 2018 [Internet]. Jakarta: Kementerian Kesehatan Rl; 2019 [cited 2020 Sep 3]. 614 p. Available from: https://ia600901.us.archive.org/17/items/LaporanRiskesdas2018NasionalPromkes.net/Laporan \%20Riskesdas\%202018\%20Nasional\%20-\%20Promkes.net.pdf

3. Sidhi, Sulastri D. Faktor risiko hipertensi pada siswa SMU Adabiah di kota Padang. Majalah Kedokteran Andalas. 2011 Aug;35(2): 147-58.

4. Perkumpulan Endokrinologi Indonesia (Perkeni). Panduan Pengelolaan Dislipidemia di Indonesia - 2015. Jakarta: PB. Perkeni; 2015. 51 p.

5. Senduk B, Bodhi W, Kepel BJ. Gambaran profil lipid pada remaja obes di Kota Bitung. e-Biomedik (e-Bm). 2016;4(1): 122-7.

6. Eker HH, Taşdemir M, Mercan S, Mucaz M, Bektemur G, Şahinoz S, et al. Obesity in adolescents and the risk factors. Turk J Phys Med Rehab. 2018 Mar;64(1):37-45.

7. Özdemir A. Adolescent obesity. Int J Caring Sci. 2015 May;8(2): 484-7.

8. Menezes IHCF, Neutzling MB, Taddei JAAC. Risk factors for overweight and obesity in adolescents of a Brazilian University: a case-control study. Nutr Hosp. 2009;24(1):17-24.

9. Williams SE, Greene JL. Childhood overweight and obesity: Affecting factors, education and intervention. J Child Obes [Internet]. 2018 [cited 2020 Sep 3];3(2): 1-7. Available from: https://childhood-obesity.imedpub.com/childhood-overweight-and-obesity-affecting-factorseducation-and-intervention. php?aid=22485 DOI: 10.21767/2572-5394.100049

10. Cook S, Kavey REW. Dyslipidemia and pediatric obesity. Pediatr Clin North Am. 2011 Dec;58(6): 1363-73.

11. Klop B, Elte JWF, Cabezas MC. Dyslipidemia in obesity: mechanisms and potential targets. Nutrients. 2013 Apr;5(4): 1218-40.

12. Tandra HJR, Bodhi W, Kepel BJ. Perbedaan profil lipid pada remaja obes dan tidak obes di Kecamatan Bolangitang Barat. e-Biomedik (eBm). 2016 Dec;4(2): 1-8.

13. Reuter CP, da Silva PT, Renner JDP, de Mello ED, Valim ARM, Pasa L, et al. Dyslipidemia is associated with unfit and overweight-obese children and adolescents. Arq Bras Cardiol. 2016 Mar;106(3):188-93.

14. Elmaogullari S, Tepe D, Uçaktürk SA, Kara FK, Demirel F. Prevalence of dyslipidemia and associated factors in obese children and adolescents. J Clin Res Pediatr Endocrinol. 2015 Sep;7(3):228-34.

15. Lozano P, Henrikson NB, Morrison CC, Dunn J, Nguyen M, Blasi PR, et al. Lipid screening in childhood and adolescence for detection of multifactorial dyslipidemia: evidence report and systematic review for the US Preventive Services Task Force. JAMA. 2016 Aug;316(6):634-44. 